\title{
EDITOR'S CHOICE
}

\section{The $B M J$ and sponsorship}

\author{
Fiona Godlee editor in chief, BMJ
}

Last year we asked for your views on whether the $B M J$ should accept sponsorship for some of its content and activities. We realised that doing this was taking a bit of a risk-even raising the issue might be seen as suggesting that we were about to relax our rules. But we were hoping to get a sense from you about how much you were bothered by such things, whether we as editors were right to fret, and whether we should keep turning down sponsorship requests. At the time, we were actively seeking ways to fund new activities at the journal, such as BMJ Spotlights (collections of articles on a topical but non-clinical issue, such as climate change (bmj.com/bmj-series/spotlightclimate-change)) and roundtable discussions, so it must have seemed perverse to our commercial colleagues and to potential sponsors to be saying no to money when it was offered.

We had lots of questions. Should we take sponsorship at all? If so, should we distinguish between commercial and non-commercial sponsors? Were drug and device companies materially different from other commercial sponsors? And what did the new buzzword "partnership" really mean? Should sponsors be allowed to suggest topics and contributors, and should they be allowed to have a representative on a judging panel or roundtable discussion?

We posted a survey on bmj.com in September 2013. We also commissioned a head to head debate, which is published this week (doi:10.1136/bmj.g352), along with an online poll (bmj. com).

Only a very small number of readers responded to the survey, so this was by no means a piece of science, but in the spirit of transparency and data sharing we have provided the results as a link from this article. Those who did respond were not keen on sponsorship in general and even less keen on pharmaceutical sponsorship in particular. There was a clear negative attitude towards allowing sponsors to have input or take part in the activities they funded. Free text comments expressed fear and counselled caution on the grounds that accepting sponsorship would damage the $B M J$ 's reputation for independence.

Small though the response was, it reassured us. It fitted our current policy and strengthened our resolve. Our current practice is that we accept sponsorship for a very limited range of activities: The BMJ Awards, BMJ Spotlights, and BMJ Roundtables. Decisions to accept sponsorship are entirely at my discretion as editor. The $B M J$ retains full editorial control. Sponsors do not take part in the activity they are funding-for example, as judges of The BMJ Awards or as members of a discussion panel. All sponsorship is declared.

But this is part of an ongoing conversation with sponsors and our commercial colleagues. It is an issue that all journals and publishers have to come to terms with one way or another. Stringent rules may mean that willing sponsors are few and far between. Or it may mean that the values that sit behind these rules attract sponsors and funders who wish to be associated with a trusted brand. For example, we have recently been awarded two sizeable grants-from the European Union and from the Open Society Foundations - to support our programme of $B M J$ investigations. We prize our independence and are glad to think you do too. We would welcome your views.

Cite this as: BMJ 2014;348:g1804

๑ BMJ Publishing Group Ltd 2014 